Article

\title{
The Role of Hazard and Vulnerability in Modulating Economic Damages of Inland Floods in the United States Using a Survey-Based Dataset
}

\author{
Qianqian Zhou ${ }^{1} * \mathbb{C}$, Jiongheng Su ${ }^{1}$, Guoyong Leng ${ }^{2}$ and Jian Peng ${ }^{3} \mathbb{C}$ \\ 1 School of Civil and Transportation Engineering, Guangdong University of Technology, \\ No.100 Waihuan Xi Road, Guangzhou 510006, China \\ 2 Environmental Change Institute, University of Oxford, Oxford OX1 3QY, UK \\ 3 School of Geography and the Environment, University of Oxford, Oxford OX1 3QY, UK \\ * Correspondence: qiaz@gdut.edu.cn
}

Received: 11 June 2019; Accepted: 2 July 2019; Published: 9 July 2019

\begin{abstract}
This study investigates the trends in economic damages caused by three types of inland floods (flash flood, flood, and heavy rain) in the United States and the variations in related hazard and vulnerability indicators between 1996 and 2016. We explore the underlying mechanisms based on a survey-based dataset maintained by the National Oceanic and Atmospheric Administration (NOAA) National Weather Service. An annual average of 6518 flood occurrences was reported, which caused economic damages of 3351 million USD per year. Flash flood and flood contributed to $53 \%$ and $32 \%$ of total occurrences and was associated with a larger share of damaging events (SDE). Results show that the higher impacts by flood and flash flood on property and crop are partly attributed to the greater intensity of rainfall. In addition, flood has the highest unit cost of damages. Notably, despite an upward tendency in economic damages by flash floods, no evident change trend is observed for inland floods as a whole. Further analysis shows changes in economic damages by heavy rain and flash flood are mainly governed by the increased annual frequency and hazard intensity, but the change of trend in their vulnerability indicators (i.e., SDE and Damage Per Event (DPE)) is not obvious. Regarding floods, it was not possible to attribute the variations in economic losses to hazard and vulnerability, as no significant tendency is found except for an increasing SDE. Despite limitations of length of records, data collection, and methodology, the difference in economic impacts and the related hazard and vulnerability revealed in this study can help better target future adaptation and mitigation measures.
\end{abstract}

Keywords: economic damages; hazard; vulnerability; flash flood; flood; heavy rain

\section{Introduction}

Flooding is one of the major natural hazards causing enormous damages to society and the environment [1-3]. Globally, economic losses resulting from flooding exceeded 19 billion USD in 2012 and have exhibited a rising trend over the past half century [4,5]. The United States is one of the most affected countries by flooding in terms of economic and human losses [6-9]. Annual losses caused by flooding have almost tripled from 1.7 billion USD per year in the 1950s to 5 billion USD per year in the 1990s (all in 1995 dollars) [10]. In the 2017 NOAA Billion-Dollar Weather and Climate Disasters datasets, flooding is identified as one of the top natural hazards with economic damages exceeding 1 billion USD [11,12]. The US Climate Extremes Index also shows that, just between 1998 and 2013, the three most extreme flooding years of the past century have occurred [6,7]. Within the context of global warming, a growing number of studies have shown concerns about rising damages due to increases in 
flood hazard and vulnerability at the global and regional scales [13-18]. Understanding recent changes in flood-induced damages and the mechanism is critical for reducing flood risk in the future $[13,18,19]$.

Changes in flood damages can be attributed to not only the changing precipitation patterns (i.e., frequency and intensity) but also the changes in vulnerable population and assets in flood-prone areas (i.e., socioeconomic factors) [20-23]. Disentangling the relative contribution of these factors to damages can help better understand the underlying mechanism of flood risk chain and mitigate the impacts in a changing environment. Previous studies showed a strong relationship between flood hazard and damages [24-26]. For example, Pielke and Downton [10] found that, at the national level, the two-day heavy rainfall events and the number of wet days are highly correlated with observed flood damages in the United States. Mallakpour and Villarini [27] reported that an increasing frequency of flooding in the central United States between 1962 and 2011 mainly resulted from changes in seasonal rainfall. On the other hand, a large number of studies argued that the upward trends of flood damages are mainly driven by the growth of population and wealth, lifestyle and demographic shifts [2,28-33].

Hazard is typically measured by intensity and depth of precipitation, runoff and inundation depth, frequency, duration and extent of flood event $[10,26,34]$, while vulnerability is mainly characterized with highly aggregated indicators such as gross domestic product (GDP) and population growth $[30,33,35,36]$. Recently, indicators have been designed to better represent regional vulnerability. For example, Peduzzi, et al. [37] assumed that the ratio of people killed to the total number of people exposed to tropical cyclones would be higher in more vulnerable regions. Similarly, Wu et al. [38]; Tanoue, Hirabayashi and Ikeuchi [21]; and Jongman, Winsemius, Aerts, Coughlan de Perez, van Aalst, Kron, and Ward [22] described vulnerability based on the proportions of economic damages and fatalities to the exposed assets and population.

Building upon previous studies, we investigate historical changes in three types of inland flood damages and the underlying drivers in the United States using a survey-based dataset only. The detailed event-based records allow for examination of flood damage components without relying on model simulations as adopted in most previous studies. A series of impact metrics are adopted to reflect hazard (i.e., occurrences and depth of precipitation) and vulnerability (i.e., share of damaging events and damage per event) for attribution analysis to identify the most influential factors. Furthermore, this study intercompares the changes in economic damages caused by heavy rain, flood, and flash flood, respectively, which have not been examined before. The insights gained from this study have implications for better management of flood risk in the future.

\section{Data and Methodology}

\subsection{Survey-Based Records of Flooding}

All analyses in this study are based on flood records obtained from the Storm Events Database (https://www.ncdc.noaa.gov/data-access/severe-weather), which is compiled by the National Oceanic and Atmospheric Administration's (NOAA's) National Climatic Data Center (NCDC). The dataset [39] provides detailed information of various types of flood events from 1996 to present, including type of event, occurrence time (beginning and ending time), location (e.g., state, county, latitude, and longitude), event source (e.g., trained spotter and law enforcement; see details in Reference [39]), economic damages (property and/or crop damages), and human casualties (direct and indirect fatalities and injuries, and locations), magnitude of event, textual description of event (narrative), and pictures.

There are five types of flood-related events in the dataset, including coastal flood, flash flood, flood, heavy rain (considered as pluvial flood), and lakeshore flood. There is a limited number of lakeshore flood which are, thus, excluded in the analysis. Regarding coastal flood, the data preparer determines the boundary between coastal and inland areas, where flood events will be encoded as flash flood or flood. As this study looks into inland floods, we only chose three types of floods: heavy rain (HR), flood (F), and flash flood (FF). According to the official instruction, flood refers to any high flow, overflow, or inundation by water which causes damage. In general, this would mean the inundation 
of a normally dry area caused by an increased water level in an established watercourse or ponding of water that poses a threat to life or property. Flash flood refers to a life-threatening, rapid rise of water into a normally dry area beginning within minutes to multiple hours of the causative event (e.g., intense rainfall, dam failure, and ice jam). Generally, it is considered that a flash flood has higher and faster impacts on life or property. That means an ongoing flood can intensify to a shorter-term flash flood in cases where intense rainfall results in a rapid surge of rising flood waters. Conversely, a flash flood can transition into a flood as rapidly rising waters abate. Note that the dataset preparer uses professional judgment in determining when the event is no longer characteristic of a flash flood and becomes a flood. Detailed explanations of the three types of inland floods can be found in the dataset instructions [38].

Snow is an important source of floods. There are two types of snow identified in the dataset: (1) Heavy snow: snow accumulation meeting or exceeding the locally/regionally defined 12- and/or 24-hour warning criteria. This could mean values such as 101.6, 152.4, or 203.2 millimeters or more in 12 hours or less or 152.4, 203.2, or 254 millimeters in 24 hours or less. (2) Lake-effect snow: convective snow bands occur in the lee of large bodies of water (e.g., the great lakes) when relatively cold air flows over warm water. Note that these two types of snow are excluded in the analysis. As for the three types of floods investigated, the impacts of snow are taken into account as there are records on snow depth in the narrative (mostly in flood and flash flood events) when it is relevant. Here is one example of event narrative describing snow condition: snow cover, which ranged from 25.4 to 177.8 millimeters along the border to as much as 762 millimeters in northwest Iowa at the beginning of the month, was gone by March 17 . The combination of snow melt and rainfall pushed nearly all Iowa rivers above the flood stage with major flood reported at some northern Iowa locations.

\subsection{Impact Metrics and Data Analysis}

This study characterizes flood economic damages as a joint function of hazard and vulnerability indicators [10,23,40-42]. As shown in Table 1, several impact metrics are defined: (1) economic damages in USD, including property and/or crop losses; (2) number of flood events, reflecting the annual total occurrences; (3) number of valid events, referring to the events with recorded economic damages greater than zero; (4) intensity of floods by means of rainfall depth. Note that the dataset does not provide direct reports on the quantitative values of hazard parameters but offers a textual description and episode narrative of each event, describing the synoptic meteorology associated with each event (e.g., depth of rainfall, wind of speed, duration of event, and the main impacts and damages). Rainfall intensity would be more preferable to describe hazard; nevertheless, there is very limited description provided by the dataset, and rainfall depth is the most frequently recorded parameter to be compared among the three types of floods in the narrative. We manually went through the relevant data list and extracted the rainfall depth as a proxy of hazard intensity. (5) Share of damaging events is defined as the ratio of valid events to the total number of events. This indicator is used to partly reflect regional vulnerability, building upon previous studies on vulnerability characterization $[21,37,38]$. Finally, (6) damage per event is defined as the ratio of total annual damages to the number of total events.

We estimated the change trends of these impact metrics during the study period (1996-2016). The statistical analysis was conducted using the polynomial curve fitting function provided by the software package MATLAB 2015a. The purpose is to quickly evaluate the primary effects of the various indicators and, thus, to identify the significant ones that contribute to the economic damages. The tendency is further tested using the corrcoef function that assesses the correlation coefficients and the related $p$-values for the indicators. Due to the limitation of data quality, we tested the statistical significance of the trend at the $90 \%$ confidence level (alpha $=0.1$ ). 
Table 1. Descriptions of impact metrics.

\begin{tabular}{cc}
\hline Impact Metrics & Descriptions \\
\hline Damage & Total annual Damages $(D)$ in USD \\
\hline Hazard & Number of Total Events (NTE); Number of Valid Events $(N V E)$ \\
Intensity, i.e., depth of precipitation
\end{tabular}

\section{Results and Discussion}

\subsection{Changes in Economic Damages}

Figure 1 shows that flood is the most devastating flood type, followed by flash flood and heavy rain, resulting in an average economic damage of 1939, 1344, and 68 million USD per year, respectively. The damages caused by flash flood have exhibited a statistically increasing trend during the past two decades, while no significant change trend is observed for flood and heavy rain. As shown in Figure $1 \mathrm{~b}$, the three types of floods are more likely to cause economic damages within the range of 0.01-0.1 million USD. Further, given the low mean annual damages by heavy rain, the results imply that impacts of heavy rain on property and crop damages are less devastative in comparison to flood and flash flood. One possible explanation could be that impacts of heavy rain are often less widespread and associated with smaller strength and size, which will be examined in the following analyses. Also, from an economic point of view, the results show that flood and flash flood need more attention in terms of disaster management.
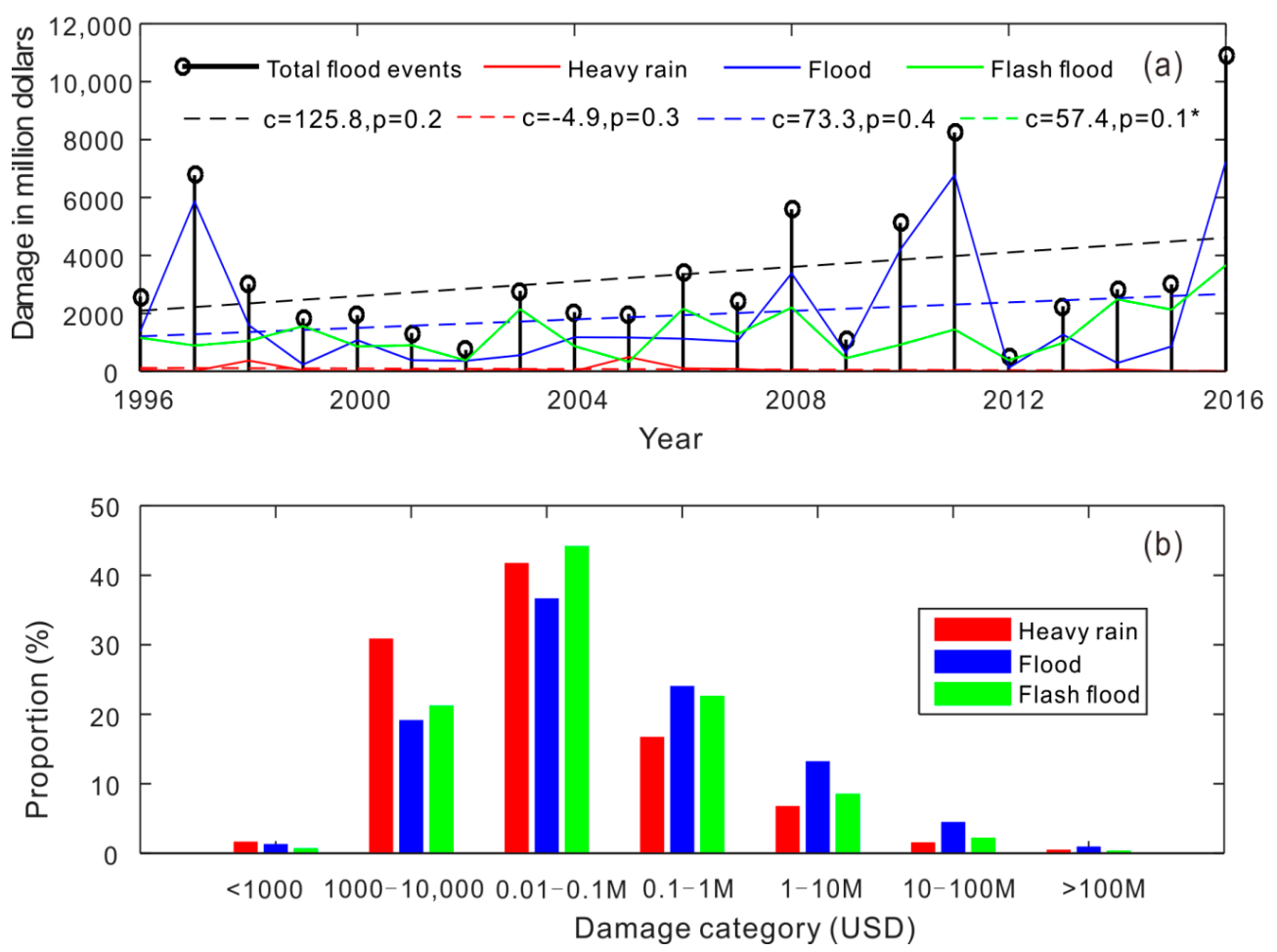

Figure 1. (a) Changes in annual economic damages and (b) proportion of damage categories (in USD) of heavy rain, flood, and flash flood during 1996-2016. For each flood type, the dashed line describes the trend, and the two numbers in the legend indicate the change trend (i.e., c-slope of the trend line) and associated statistical significance (i.e., $p$-value), respectively. The trends that are statistically significant at the $90 \%$ confidence level are highlighted with asterisks $\left(^{*}\right)$. 


\subsection{Hazard}

The occurrences of heavy rain are much less frequent compared to the other types of floods (Figure 2). Between 1996 and 2016, heavy rain, flood, and flash flood have annual averages of 969, 2072, and 3476 events, respectively, of which 62,702, and 1332 events per year have caused tangible damages, respectively. Importantly, in contrast to the change patterns in annual damages, significant upward trends in occurrences are found in most flood types despite their large variations. Further analysis on the three types of floods with statistics on property or crop loss shows that, generally, an increasing tendency is observed in the hazard frequency for most floods with or without taking into economic damages. This can be an effect of climate change that exacerbates the occurrences of hazard events, and the hazard occurrence is likely to continue increasing in the future. In addition, the results indicate that the decreasing annual damages of heavy rain are not a result of the changing occurrences but of other types of impact factors, possibly the hazard intensity or vulnerability. Given the large share of million-dollar damaging events (Figure 1b) and high number of valid events (Figure 2b), the results show that damages caused by flood and flash floods are much more severe and frequent. Priorities should, thus, be given to mitigate the damages from these two types of floods.

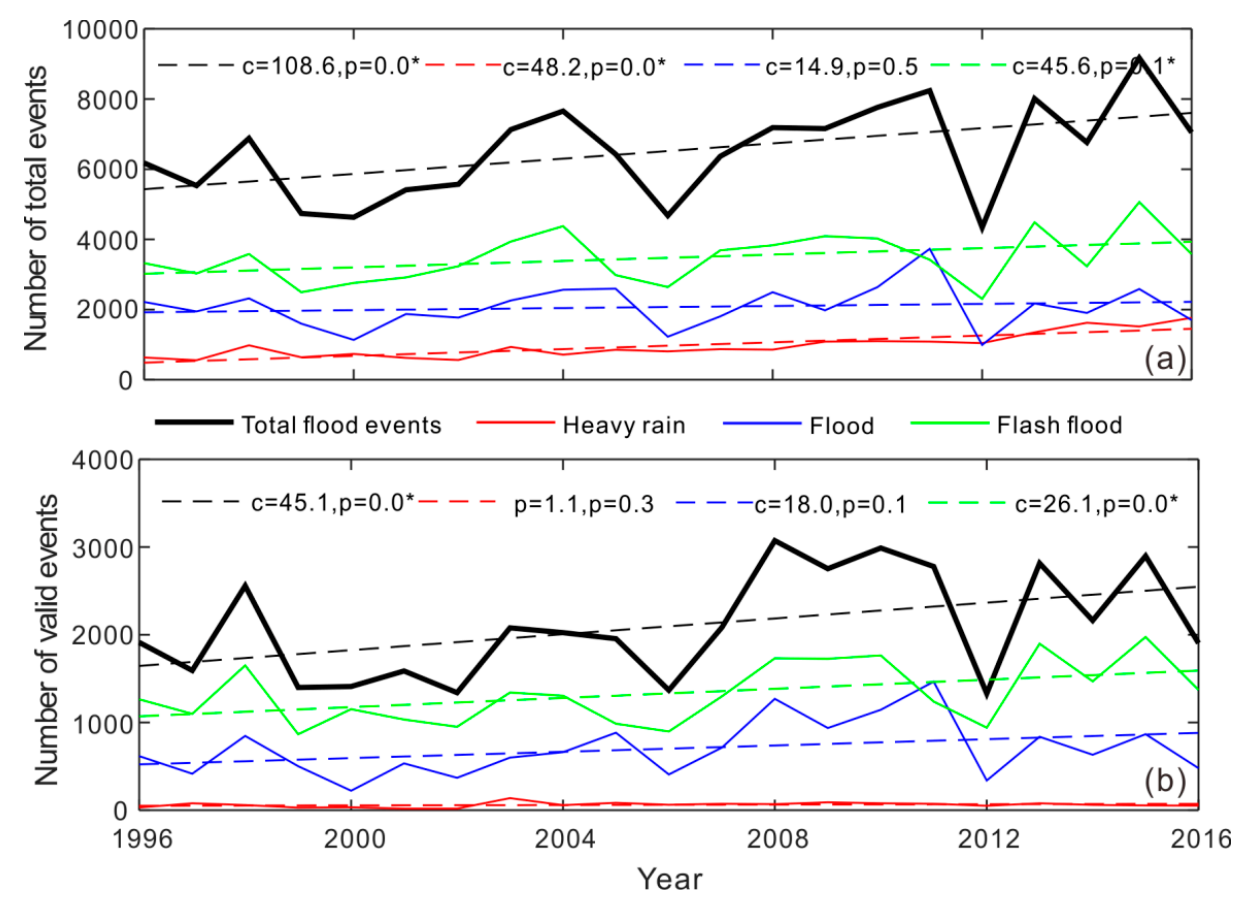

Figure 2. Changes in (a) number of total flood events and (b) number of valid events of heavy rain, flood, and flash flood during 1996-2016. For each flood type, the two numbers in the legend indicate the change trend (i.e., c-slope of the trend line) and associated statistical significance (i.e., $p$-value), respectively. The trends that are statistically significant at the $90 \%$ confidence level are highlighted with asterisks $\left({ }^{*}\right)$.

Similarly, as shown in Figure 3a, the variation of hazard intensity (i.e., rainfall depth) associated with heavy rain is smaller than the other two types of floods. More extreme rainfall depths were observed during flood and flash flood events. The distribution of event rainfall depth ranges from 0.254 to 812.8 millimeters for heavy rain, while the upper extremes increased to 1219.2 millimeters for both flood and flash flood. An average of 154.94 millimeters per event is estimated for flash flood, followed by 149.86 and 99.06 millimeters per event for flood and heavy rain. This is in line with the event description in the dataset that flash flood is generally associated with short-term but more intensified rainfall and often results in a rapid surge of rising waters. In terms of accumulated annual rainfall depth, upward trends are 
found in all types of inland floods except for flood (the trend is not statistically significant). The results imply that the hazard of flood has generally increased over the study period.
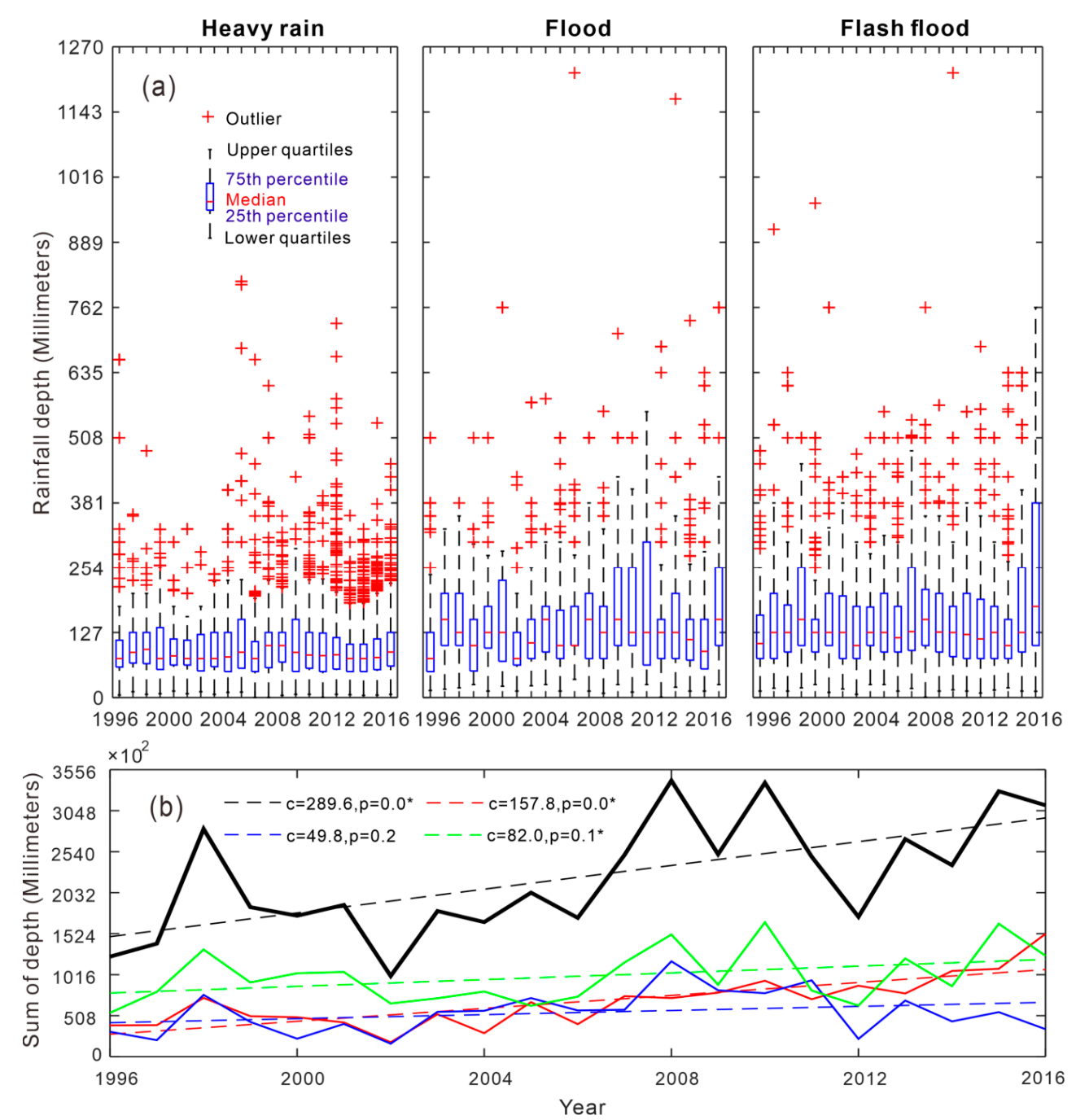

Figure 3. (a) Statistics of hazard intensity (rainfall depths in millimeters) and (b) changes in annual accumulated rainfall depth for heavy rain, flood, and flash flood during 1996-2016. For each flood type, the dashed line describes the trend and the two numbers in the legend indicate the change trend (i.e., c-slope of the trend line) and associated statistical significance (i.e., p-value), respectively. The trends that are statistically significant at the $90 \%$ confidence level are highlighted with asterisks $\left(^{*}\right)$.

\subsection{Vulnerability}

The SDE distributions for flood and flash flood vary from $20 \%$ to $51 \%$ and from $29 \%$ to $46 \%$, with average values of $33 \%$ and $38 \%$, respectively (Figure $4 a$ ). This means more than one third of these flood events have caused damages to property and crop. By contrast, the distribution of damaging heavy rain is much lower, ranging from $2 \%$ to $15 \%$, with an average value of $7 \%$. This can be partly due to the less intensified rainfall associated with the type of event, which does not pose a significant threat to property or crop in the same ways flash flood or flood do. Note that only the annual SDE of flood has showed an increasing trend during the past two decades. Figure $4 \mathrm{~b}$ shows that, in general, flood leads to the highest unit cost of damage. In extreme cases, the flood event cost is up to 4.26 and 3.01 million USD in 2016 and 1997 respectively, while the maximum DPE of heavy rain is 0.58 million USD in 2005. Notably, none of the DPE trends is statistically significant, which may be due to the limitation of the record length in this study. 

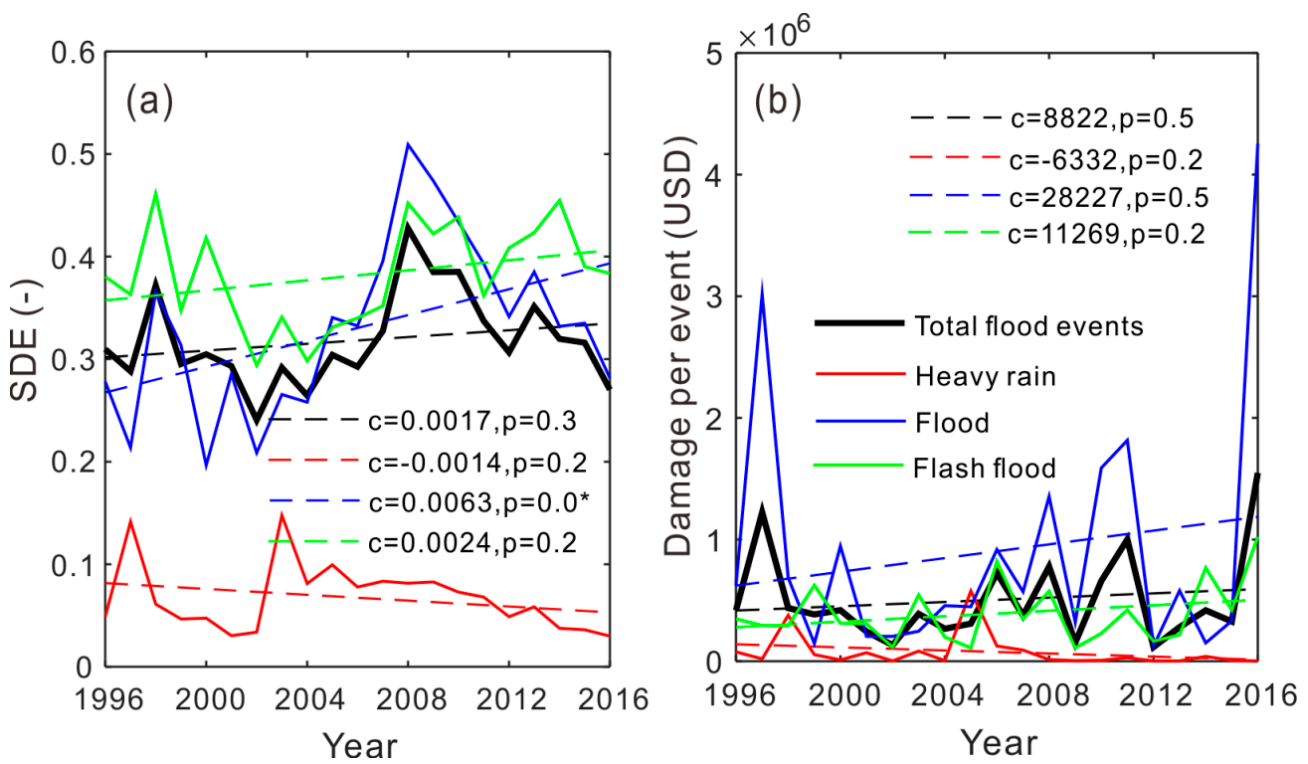

Figure 4. Changes in (a) Share of Damaging Events and (b) Damage Per Event for the three types of flooding during the study period. The two numbers indicate the change trend and associated $p$-value, respectively. The trends that are statistically significant at the $90 \%$ confidence level are highlighted with asterisks $\left.{ }^{*}\right)$.

In terms of monthly variations, damaging events tend to occur most frequently during summer (June and October) for heavy rain and flash flood (Figure 5a). Their mean SDEs are up to $45 \%$ and $54 \%$ in June and October, respectively, while the mean values dropped to $12 \%$ and $8 \%$ in December and February, respectively. Flood has relatively high SDEs from March to October, with mean SDEs of 33\% and 32\% in spring and summer, respectively. As expected, most damages occurred during the monsoon/rainy seasons when there is plenty of rainfall. Differences between hourly SDEs are relatively small in comparison to seasonal SDEs (Figure 5b). For heavy rain and flash flood, hours 12-17 is the time period that has the highest SDE, whereas hours 6-11 are the peak period of damaging events for flood.
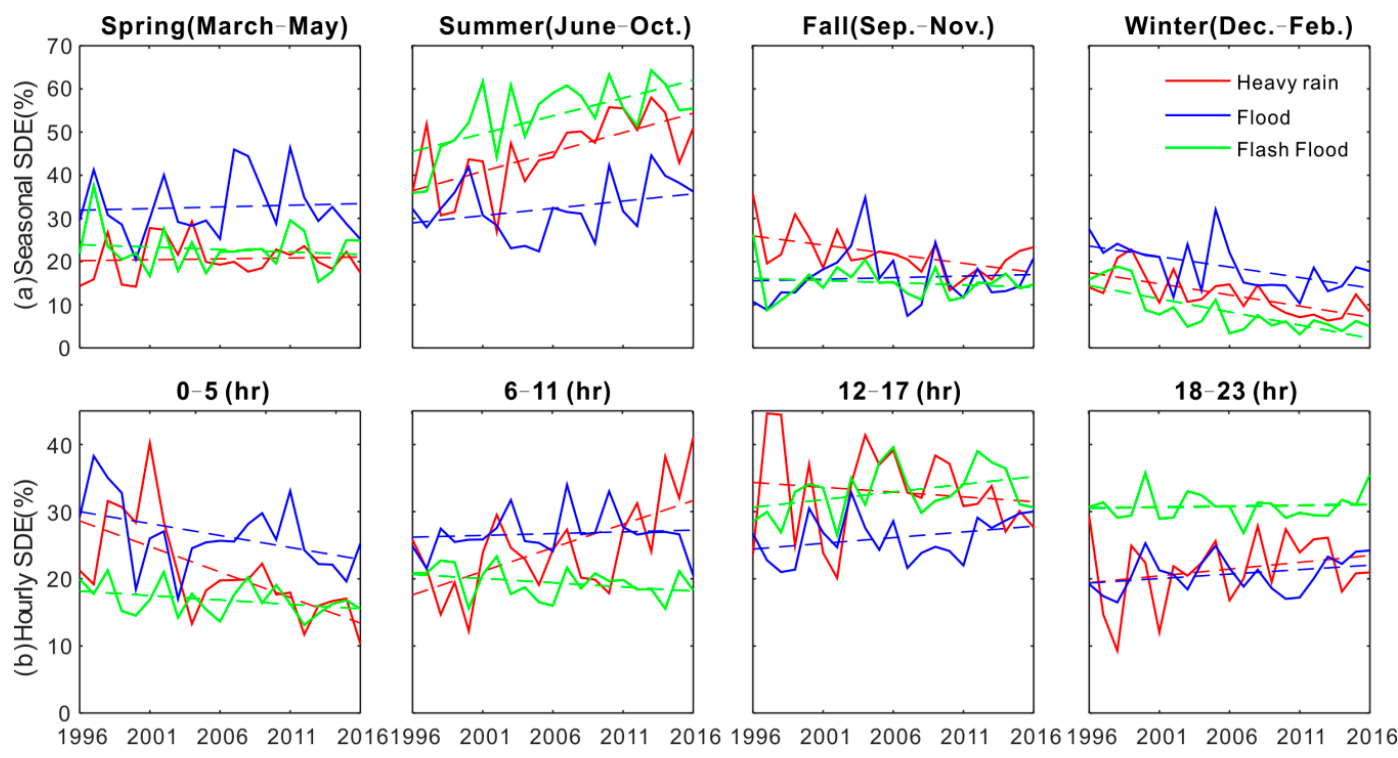

Year

Figure 5. (a) Seasonal and (b) hourly Share of Damaging Events of the three types of floods. 


\subsection{Attribution Analysis of Key Indicators}

It is shown that the annual occurrences of all types of floods have an increasing trend. However, there are no evident change trends in annual economic damages caused by different types of flood events, except for flash flood with an upward trend. To better understand the mechanism behind this phenomenon, Figure 6 summaries how the trends in the examined hazard and vulnerability indicators might influence the variations in economic damages. For heavy rain, an increasing hazard trend is observed for both occurrence and intensity, while an insignificant downward slope is found for vulnerability indicators (i.e., SDE and DPE). It is thus assumed that the dynamics of heavy rain damages are likely caused by the variations in vulnerability. Regarding flood, changing signals of hazard and vulnerability are less obvious. Despite the increase in SDE over the study period, change trends in the economic losses and the rest hazard and vulnerability indicators are not statistically significant. In terms of flash flood, increases in annual damages are partly attributed to the increase in hazard. It is difficult to quantify the contribution of vulnerability to the changing damages, as the trends in neither SDE nor DPE are found to be statistically significant. The difficulty in attributing the changing economic damages to hazard and vulnerability can be a combined result of the complex mechanisms behind flood damages and the lack of sufficient data (i.e., length of records and types of variables recorded) in this study. This makes it more uncertain to further attribute the observed trends in economic damages to regional vulnerability.

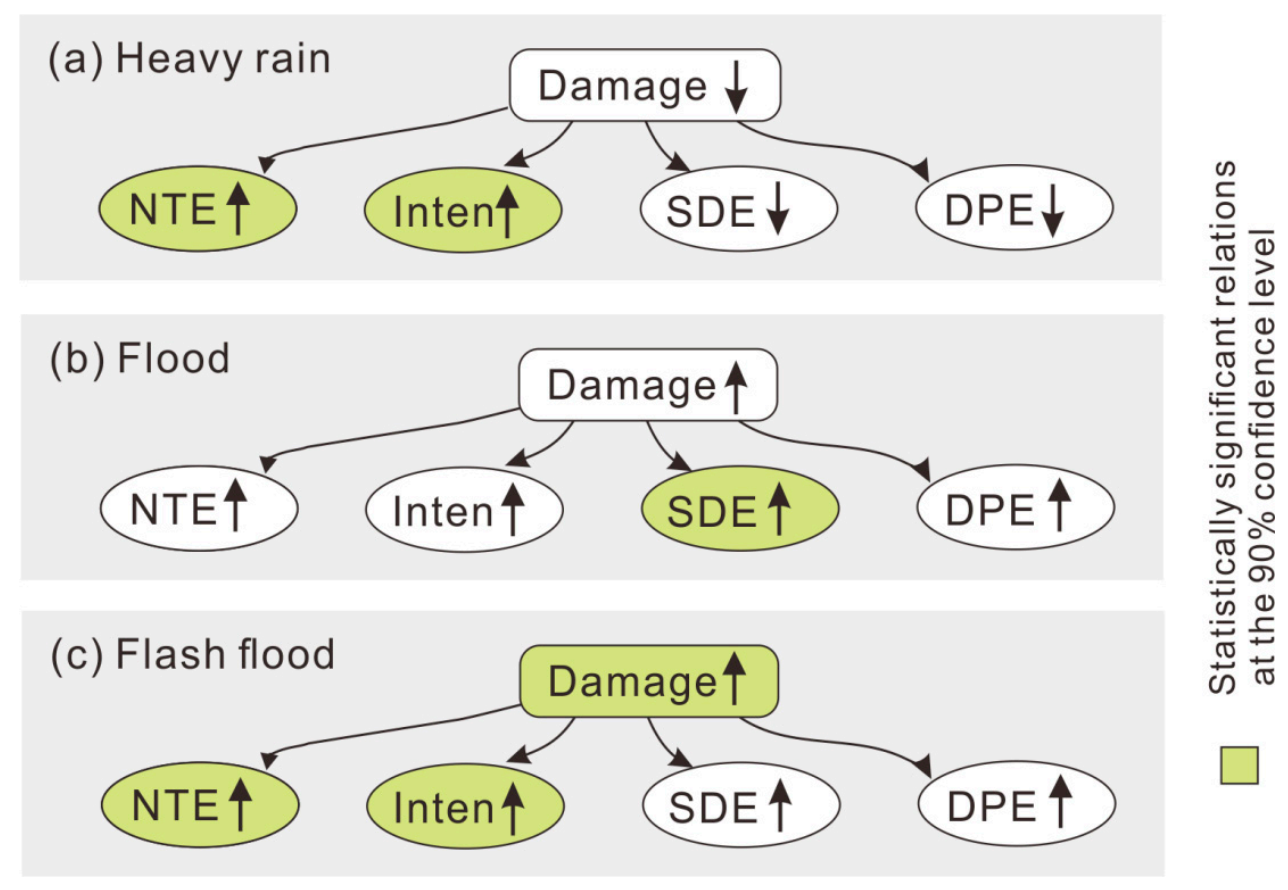

Figure 6. Attribution analysis of changing damages for the three types of inland floods. The arrows indicate the trend of changes, in which an upward arrow refers to an increasing tendency and vice versa.

\section{Summary and Conclusions}

Understanding historical trends in flood damages and the underlying drivers is important for better adaptation and mitigation. This study investigates the evolutions of hazard and vulnerability for three main types of inland floods, namely heavy rain, flood, and flash flood, in the United States from 1996 to 2016. Unlike commonly adopted modeling approaches, this study performs an attribution analysis using a survey-based dataset to provide insights into patterns in economic damages and to quantify the role of hazard and vulnerability in conditioning the damages. In particular, the results address the difficulties in characterizing regional vulnerability to annual losses due to its high variability, complexity, and uncertainty. 
In total, floods have caused an annual average of 6518 occurrences and economic losses of 3351 million USD per year, among which flash flood and flood contributed the most (i.e., $53 \%$ and $58 \%$, respectively). In comparison to heavy rain, the number and intensity of damaging events induced by flood and flash flood are much larger, resulting in more severe and frequent damages (e.g., with a higher share of million-dollar events). At the national level, higher priority should be given to the two types of floods due to their bigger economic impacts. Heavy rain is found to be associated with less intensified rainfall and lower impacts on property or crop. This study also found that there is no significant trend in economic damages caused by the different types of floods, except for an upward tendency of flash flood. For heavy rain, increasing hazards are observed in terms of annual frequency and rainfall depth. However, the change trend in vulnerability indicators SDE and DPE is not obvious. Regarding flood, it is found that regional SDE has increased over the study period. Nevertheless, no significant tendency is found in the other hazard and vulnerability indicators. In terms of flash flood, results show that the increasing annual damages are partly attributed to the increased hazard.

Several limitations in this study should be acknowledged. Firstly, the length of records is limited despite the NOAA dataset being one of the most comprehensive and consistent sources for historical flood records. More robust conclusions require longer data records, which is currently not publicly available and thus beyond the scope of this study. Importantly, an investigation of more explainable hazard and vulnerability indicators in the dataset is required to better understand the change trend and the underlying mechanisms of flood damages. One great obstacle for further quantitative assessment is the lack of accurate field-level data on both hazard and vulnerability characterization. As mentioned before, the hazard description in the dataset is compiled in the event/episode narrative format rather than a table/data list, which requires huge efforts and time to extract the related hazard parameters (i.e., rainfall depth and wind speed). There is also a lack of vulnerability description in the records due to difficulties in collecting socioeconomic variables (i.e., exposed assets or population, regional economic condition, flood control, and defense capacities).

Further, flood risk is usually a combined product of hazard, exposure, and vulnerability. Changes in flood damage are attributed to not only the frequency and magnitude of hazard but also the level of exposure (e.g., population and economic assets) and vulnerability (the susceptibility of the exposed elements to hazards). In this study, hazard indicators include the rainfall depth and occurrences, whereas it is difficult to separate the vulnerability and exposure explicitly due to data limitation. Although this study adopted two vulnerability indicators building upon previous literature, further identification and development of additional explanatory variables are necessary. The results will be more significant if there is an exposure assessment combined. Unfortunately, due to the lack of spatial data on land-use and historical population growth, the current analysis is conducted at the national level without exploring the spatial patterns. Regarding future research, this study only looked into the economic damages, and other impacts of floods such as social and environmental impacts [43-45] were not investigated and could be explored in the future.

This study acknowledges the presence of uncertainty in the dataset and analysis. First, the data collection and processing can introduce uncertainties due to quality of input data, level of details of the narratives, and misreading the values, which will consequently affect the reliability of the results. There are also uncertainties in, e.g., evaluating the impacts (i.e., property and/or crop damage values), categorization of event type, selection and measuring the hazard indicators, and survey and recording process. For example, it is noted that using rainfall depth may introduce uncertainty and/or biased estimates in hazard description as it is the product of duration and intensity. Also, though the use of SDE is based upon earlier studies [21,37,38], the approach can introduce uncertainty in describing regional vulnerability. Similarly, the use of DPE is based on the assumption that the average impact of flood events will be higher in vulnerable regions than in less vulnerable areas. This indicator can only partly reflect vulnerability as an event that can cause more damage simply due to its greater intensity even if the vulnerability of the affected people/assets remains unchanged. We acknowledge 
the uncertainty and limitation of the adopted methodology and suggest using more detailed spatial data on building and/or land values in the future to reflect vulnerability when data is available.

Despite these limitations, the results obtained in this study provide valuable insights to recent change tendencies and drivers for heavy rain, flood, and flash flood on economic damages, which will help, e.g., the Federal Emergency Management Agency (FEMA) and federal and state agencies in the future to better understand the impact mechanism of the hazard and vulnerability of the three types of inland floods and to identify the key influencing factors in modulating flood risks. The revealed difference in economic impacts and related hazard and vulnerability characterization helps inform strategies for reducing risk of various flood types in the future. Such information is essential to decision makers and responsible authorities to properly formulate defense, mitigation, and management measures aiming to reduce socioeconomic damage.

Author Contributions: Conceptualization, Q.Z. and G.L.; methodology, Q.Z. and G.L.; analysis and discussion: Q.Z., J.S., G.L., and J.P., writing Q.Z., J.S., G.L., and J.P.

Funding: This research was funded by the National Natural Science Foundation of China (Grant No. 51809049), the Science and Technology Program of Guangzhou, China (Grant No. 201804010406), and the Public Welfare Research and Ability Construction Project of Guangdong Province, China (Grant No. 2017A020219003).

Conflicts of Interest: The authors declare no conflict of interest.

\section{References}

1. Pielke, R.A. Nine fallacies of floods. Clim. Chan. 1999, 42, 413-438. [CrossRef]

2. Kundzewicz, Z.W.; Kanae, S.; Seneviratne, S.I.; Handmer, J.; Nicholls, N.; Peduzzi, P.; Mechler, R.; Bouwer, L.M.; Arnell, N.; Mach, K.; et al. Flood risk and climate change: Global and regional perspectives. Hydrol. Sci. J. 2014, 59, 1-28. [CrossRef]

3. Easterling, D.R.; Meehl, G.A.; Parmesan, C.; Changnon, S.A.; Karl, T.R.; Mearns, L.O. Climate extremes: Observations, modeling, and impacts. Science 2000, 289, 2068-2074. [CrossRef] [PubMed]

4. Philip, J.W.; Brenden, J.; Frederiek Sperna, W.; Arno, B.; Rens van, B.; Marc, F.P.B.; Willem, L.; Hessel, C.W. Assessing flood risk at the global scale: Model setup, results, and sensitivity. Environ. Res. Lett. 2013, 8, 044019.

5. IPCC. Managing the Risks of Extreme Events and Disasters to Advance Climate Change Adaptation; A Special Report of Working Groups I and II of the Intergovernmental Panel on Climate Change; Field, C.B., Barros, V., Stocker, T.F., Qin, D., Dokken, D.J., Ebi, K.L., Mastrandrea, M.D., Mach, K.J., Plattner, G.-K., Allen, S.K., et al., Eds.; Cambridge University Press: Cambridge, UK; New York, NY, USA, 2012; p. 582.

6. NOAA. US Climate Extremes Index. National Climatic Data Center, National Oceanic and Atmospheric Administration. Available online: http://www.ncdc.noaa.gov/extremes/cei/ (accessed on 5 February 2018).

7. Retchless, D.; Frey, N.; Wang, C.M.; Hung, L.S.; Yarnal, B. Climate extremes in the united states: Recent research by physical geographers. Phys. Geogr. 2014, 35, 3-21. [CrossRef]

8. Villarini, G.; Smith, J.A.; Baeck, M.L.; Krajewski, W.F. Examining flood frequency distributions in the midwest us. JAWRA J. Am. Water Resour. Assoc. 2011, 47, 447-463. [CrossRef]

9. Ashley, S.T.; Ashley, W.S. Flood fatalities in the United States. J. Appl. Meteorol. Climatol. 2008, 47, 805-818. [CrossRef]

10. Pielke, R.A.; Downton, M.W. Precipitation and damaging floods: Trends in the United States, $1932-1997$. J. Clim. 2000, 13, 3625-3637. [CrossRef]

11. NCEI. U.S. Billion-Dollar Weather and Climate Disasters. NOAA National Centers for Environmental Information (NCEI). Available online: https://www.ncdc.noaa.gov/billions/ (accessed on 12 March 2018).

12. Smith, A.B.; Katz, R.W. US billion-dollar weather and climate disasters: Data sources, trends, accuracy and biases. Nat. Hazards 2013, 67, 387-410. [CrossRef]

13. Stewart, I.T.; Ficklin, D.L.; Carrillo, C.A.; McIntosh, R. 21st century increases in the likelihood of extreme hydrologic conditions for the mountainous basins of the southwestern united states. J. Hydrol. 2015, 529, 340-353. [CrossRef]

14. Takeuchi, K. Increasing vulnerability to extreme floods and societal needs of hydrological forecasting. Hydrol. Sci. J. 2001, 46, 869-881. [CrossRef] 
15. Huang, S.; Leng, G.; Huang, Q.; Xie, Y.; Liu, S.; Meng, E.; Li, P. The asymmetric impact of global warming on us drought types and distributions in a large ensemble of 97 hydro-climatic simulations. Sci. Rep. 2017, 7, 5891. [CrossRef] [PubMed]

16. Leng, G.; Tang, Q.; Rayburg, S. Climate change impacts on meteorological, agricultural and hydrological droughts in china. Glob. Planet. Chang. 2015, 126, 23-34. [CrossRef]

17. Trenberth, K.E.; Dai, A.; van der Schrier, G.; Jones, P.D.; Barichivich, J.; Briffa, K.R.; Sheffield, J. Global warming and changes in drought. Nat. Clim. Chang. 2014, 4, 17-22. [CrossRef]

18. Ntelekos, A.A.; Oppenheimer, M.; Smith, J.A.; Miller, A.J. Urbanization, climate change and flood policy in the United States. Clim. Chang. 2010, 103, 597-616. [CrossRef]

19. Parr, D.; Wang, G.L.; Ahmed, K.F. Hydrological changes in the us northeast using the connecticut river basin as a case study: Part 2. Projections of the future. Glob. Planet. Chang. 2015, 133, 167-175. [CrossRef]

20. Zhou, Q.; Mikkelsen, P.S.; Halsnæs, K.; Arnbjerg-Nielsen, K. Framework for economic pluvial flood risk assessment considering climate change effects and adaptation benefits. J. Hydrol. 2012, 414, 539-549. [CrossRef]

21. Tanoue, M.; Hirabayashi, Y.; Ikeuchi, H. Global-scale river flood vulnerability in the last 50 years. Sci. Rep. 2016, 6, 36021. [CrossRef]

22. Jongman, B.; Winsemius, H.C.; Aerts, J.C.; de Perez, E.C.; van Aalst, M.K.; Kron, W.; Ward, P.J. Declining vulnerability to river floods and the global benefits of adaptation. Proc. Natl. Acad. Sci. USA 2015, 112, E2271-E2280. [CrossRef]

23. Floodsite. Flood Risk Assessment and Flood Risk Management. An Introduction and Guidance Based on Experiences and Findings of Floodsite (An Eu-Funded Integrated Project); Deltares/Delft Hydraulics: Delft, The Netherlands, 2009; ISBN 97890840670.

24. Karl, T.R.; Knight, R.W. Secular trend of precipitation amount, frequency, and intensity in the United States. Bull. Am. Meteorol. Soc. 1998, 79, 231-242. [CrossRef]

25. Kunkel, K.E.; Andsager, K.; Easterling, D.R. Long-term trends in extreme precipitation events over the conterminous United States and Canada. J. Clim. 1999, 12, 2515-2527. [CrossRef]

26. Zhou, Q.; Leng, G.; Feng, L. Predictability of state-level flood damage in the conterminous united states: The role of hazard, exposure and vulnerability. Sci. Rep. 2017, 7, 5354. [CrossRef] [PubMed]

27. Mallakpour, I.; Villarini, G. The changing nature of flooding across the central united states. Nat. Clim. Chang. 2015, 5, 250-254. [CrossRef]

28. Changnon, S.A.; Pielke, R.A.; Changnon, D.; Sylves, R.T.; Pulwarty, R. Human factors explain the increased losses from weather and climate extremes. Bull. Am. Meteorol. Soc. 2000, 81, 437-442. [CrossRef]

29. Barredo, J.I.; Sauri, D.; Llasat, M.C. Assessing trends in insured losses from floods in Spain 1971-2008. Nat. Hazards Earth Syst. Sci. 2012, 12, 1723-1729. [CrossRef]

30. Visser, H.; Petersen, A.C.; Ligtvoet, W. On the relation between weather-related disaster impacts, vulnerability and climate change. Clim. Chang. 2014, 125, 461-477. [CrossRef]

31. Choi, O.; Fisher, A. The impacts of socioeconomic development and climate change on severe weather catastrophe losses: Mid-atlantic region (mar) and the US. Clim. Chang. 2003, 58, 149-170. [CrossRef]

32. Bouwer, L.M. Have disaster losses increased due to anthropogenic climate change? Bull. Am. Meteorol. Soc. 2011, 92, 39. [CrossRef]

33. Wing, O.E.J.; Bates, P.D.; Smith, A.M.; Sampson, C.C.; Johnson, K.A.; Fargione, J.; Morefield, P. Estimates of present and future flood risk in the conterminous united states. Environ. Res. Lett. 2018, 13, 034023. [CrossRef]

34. Barredo, J.I. Major flood disasters in Europe: 1950-2005. Nat. Hazards 2007, 42, 125-148. [CrossRef]

35. Neumayer, E.; Barthel, F. Normalizing economic loss from natural disasters: A global analysis. Glob. Environ. Chang. 2011, 21, 13-24. [CrossRef]

36. Hallegatte, S.; Green, C.; Nicholls, R.J.; Corfee-Morlot, J. Future flood losses in major coastal cities. Nat. Clim. Chang. 2013, 3, 802-806. [CrossRef]

37. Peduzzi, P.; Chatenoux, B.; Dao, H.; De Bono, A.; Herold, C.; Kossin, J.; Mouton, F.; Nordbeck, O. Global trends in tropical cyclone risk. Nat. Clim. Chang. 2012, 2, 289. [CrossRef]

38. Wu, J.; Han, G.; Zhou, H.; Li, N. Economic development and declining vulnerability to climate-related disasters in china. Environ. Res. Lett. 2018, 13, 3. [CrossRef] 
39. NWS. National Weather Service Instruction 10-1605, Storm Data Preparation. 2016. Available online: https://www.ncdc.noaa.gov/stormevents/pd01016005curr.pdf (accessed on 8 March 2018).

40. Gaume, E.; Bain, V.; Bernardara, P.; Newinger, O.; Barbuc, M.; Bateman, A.; Blaskovicova, L.; Bloschl, G.; Borga, M.; Dumitrescu, A.; et al. A compilation of data on european flash floods. J. Hydrol. 2009, 367, 70-78. [CrossRef]

41. Barredo, J.I. Normalised flood losses in Europe: 1970-2006. Nat. Hazards Earth Syst. Sci. 2009, 9, 97-104. [CrossRef]

42. Lung, T.; Lavalle, C.; Hiederer, R.; Dosio, A.; Bouwer, L.M. A multi-hazard regional level impact assessment for europe combining indicators of climatic and non-climatic change. Glob. Environ. Chang. 2013, 23, 522-536. [CrossRef]

43. Dang, N.M.; Babel, M.S.; Luong, H.T. Evaluation of food risk parameters in the day river flood diversion area, red river delta, vietnam. Nat. Hazards 2011, 56, 169-194. [CrossRef]

44. Ahmadisharaf, E.; Kalyanapu, A.J.; Chung, E.S. Sustainability-based flood hazard mapping of the swannanoa river watershed. Sustainability 2017, 9, 1735. [CrossRef]

45. Meyer, V.; Haase, D.; Scheuer, S. Flood risk assessment in european river basins-Concept, methods, and challenges exemplified at the mulde river. Integr. Environ. Assess. Manag. 2009, 5, 17-26. [CrossRef]

(C) 2019 by the authors. Licensee MDPI, Basel, Switzerland. This article is an open access article distributed under the terms and conditions of the Creative Commons Attribution (CC BY) license (http://creativecommons.org/licenses/by/4.0/). 